Article

\title{
Variables and Challenges in Assessing EU Experts' Performance
}

\author{
Cathrine Holst and Silje H. Tørnblad * \\ ARENA-Centre for European Studies, University of Oslo, 0855 Oslo, Norway; E-Mails: cathrine.holst@arena.uio.no (C.H), \\ s.h.tornblad@arena.uio.no (S.H.T.); Tel.: +47-95111916 (S.H.T) \\ * Corresponding author
}

Submitted: 17 June 2014 | In Revised Form: 5 November 2014 | Accepted: 24 November 2014 |

Published: 31 March 2015

\begin{abstract}
Expert advice in political processes is supposed to improve decisions. If expertise fails in this function, a legitimacy problem occurs: granting political power to experts may be defensible, but only on the grounds that it contributes to enlightening political processes and facilitate problem-solving. The paper provides a theoretical exploration of four variables that are key when assessing the epistemic quality of expert deliberations: the degree to which these deliberations are 1) informed by technical expertise, 2) regulated by epistemically optimal respect and inclusion norms, 3) focused on politically relevant and applicable knowledge, and 4) approaching questions involving moral judgment and standard setting competently. Previous research on the European Commission's use of expert advice has more or less overlooked the question of experts' epistemic performance, and this paper discusses the possible reasons for this in light of well-known methodological challenges in studies of elite behaviour; access and bias problems. A discussion of the merits and limitations of different available data on the Commission experts shows that the biggest obstacle in the study of experts' epistemic performance is rather the problem of epistemic asymmetry, i.e. of how researchers as non-experts can assess the epistemic quality of experts' contributions and behaviour. The paper offers, finally, a set of strategies to get research going despite this problem.
\end{abstract}

\section{Keywords}

epistemic quality; EU expertise; European Commission; expert deliberation; deliberative democracy; legitimacy

\section{Issue}

This article is part of the special issue "The Role of Expert Knowledge in EU Executive Institutions", edited by Professor Åse Gornitzka (University of Oslo, Norway) and Dr. Cathrine Holst (University of Oslo, Norway).

(C) 2015 by the authors; licensee Cogitatio (Lisbon, Portugal). This article is licensed under a Creative Commons Attribution 4.0 International License (CC BY).

\section{Introduction}

Several institutions in contemporary democracies, from central banks to supreme courts, operate on the assumption that extensive delegation of decision-making power to experts is appropriate and legitimate, and decision-making in parliaments by cabinets and other executive institutions is based routinely on expert advice. Citizens tend to accept decision-making on these terms as legitimate and place considerable trust in procedures and institutions that privilege experts and expert opinions. When they do so, this is closely connected to the belief that delegating decisions to relevant experts or relying on their advice will contribute to improving decisions; expertise is supposed to be the "filter" that secures the "truth-sensitivity" of policies and legislation (Christiano, 2012). Correspondingly, if expertise fails in this function, a legitimacy problem occurs: giving political power to experts may be defensible, but only on the grounds that it contributes to enlightening political processes and improved problemsolving (see also Martí, 2006).

If we care about the legitimacy of political institutions, it should therefore be a research priority to investigate experts' epistemic performance. This applies no less in studies of the European Union (EU): the EU's 
non-majoritarian institutions, with the European Commission at the forefront, have used knowledge and expertise as sources of legitimacy in the absence of a direct electoral mandate (Moodie, 2011; Trondal, 2001). In addition to in-house expertise, the Commission now routinely consults external experts to assist in the formulation and implementation of policy (Schaefer, 2002). This is reflected in the establishment and formalisation of an expert group system currently consisting of more than fifteen hundred groups (Gornitzka \& Sverdrup, 2008; Metz, 2013). It would seem a natural ambition for researchers to investigate how these experts perform, given what the use of expertise in political processes is supposed to be good for, and the particular urgency for non-majoritarian institutions such as the Commission to show real problem-solving abilities.

This raises the methodological question of how expert behaviour and performance can most properly be studied. This paper focuses on a key factor in assessments of experts' contribution to political processes, namely the epistemic quality of their deliberations. On the basis of relevant literature, the paper identifies a set of variables that seem vital given this focus, and also discusses the real possibilities of studying epistemic performance variables like these in the concrete context of the European Commission's expert group system. A review of previous research shows that the question of the epistemic performance of the members of these groups has thus far been peculiarly overlooked. The paper lists the different data that is available if we want to study what Commission experts do, and discusses the merits and limitations of this data in light of well-known methodological challenges in studies of elite behaviour; the access problem and the bias problem. However, the bigger obstacle seems to be the problem of epistemic asymmetry: due to their lack of expertise, non-experts cannot assess the epistemic quality of experts' judgments and justifications directly. Future research and methodological discussions must focus more consistently on ways to get around this problem, since knowledge of whether EU experts behave as they ought to is paramount for the evaluation of EU institutions' legitimacy. The paper ends by suggesting some paths towards this research objective.

The following section of the paper clarifies the concept of an epistemic dimension of democratic legitimacy and deliberation, introduces the idea of deliberative systems and the normative role of expertise arrangements within such systems, and identifies some problems with existing studies and approaches, given our specific focus on experts' cognitive performance in political processes. The third section elaborates on four central variables in any assessment of the epistemic quality of expert deliberations, namely the degree to which they are 1) informed by technical expertise, 2) regulated by epistemically optimal respect and inclusion norms, 3) focused on politically relevant and appli- cable knowledge, and 4) approaching questions involving moral judgment and standard setting competently. The elaboration is theoretical and focuses on connecting the variables to the idea of truth-sensitive deliberations in democratic political contexts. The fourth section shows how existing literature on the Commission's expert groups has paid little attention to the question of how these experts perform, and discusses the possibility of studying the epistemic quality of expert deliberation in light of access and bias problems, the problem of epistemic asymmetry, and the specific task of studying experts' deliberations, given available data. The final section concludes and proposes some strategies for future research.

\section{Political Legitimacy and Expert Performance in Deliberative Systems}

To be a desirable form of rule, democracy must have procedures with "truth-tracking" or "truth-sensitive" qualities that contribute to improving decisions (Christiano, 2012; Goodin, 2003; see also Estlund 1992, 1993, 1997, 2008); a normative defence of democracy must refer to the intrinsic moral value of democratic procedures (Lafont, 2006; Martí, 2006; Peter, 2007, 2011), but also to democracy's instrumental value and how it is a form of rule that contributes to better outcomes. Mansbridge and Parkinson (2012, p. 11) have conceptualised this aspect of democracy as democracy's epistemic dimension or "function": "The epistemic function of a deliberative system is to produce preferences, opinions, and decisions that are appropriately informed by facts and logic and are the outcome of substantive and meaningful consideration of relevant reasons." This epistemic dimension comes in addition to what Mansbridge and Parkinson (2012, pp. 11-12) refer to as the respect dimension or "ethical function" ("to promote mutual respect among citizens") and the inclusion dimension or "democratic function" of democracy ("the inclusion of multiple and plural voices, interests, concerns, and claims").

The understanding of the epistemic dimension of democracy will vary with different normative conceptions of democracy. A central distinction can be drawn between aggregative and deliberative democracy (Peter, 2011). Aggregative democracy theory regards democracy as a particular way of aggregating citizens' individual preferences to a collective choice. The key aggregative mechanism is voting. Accordingly, central topics in studies and assessments of the epistemic dimension from an aggregative democracy perspective would be the role of "facts and logic" and considerations of "relevant reasons" in voters' belief and preference formation - as in literature on public ignorance and factors influencing the quality of the aggregative decision outcomes - as in the literature on Condorcet's jury theorem (Estlund, 1994; Goodin, 2003; Talisse, 
2004; Weinshall, 2003). Our point of departure in this paper, deliberative democracy, highlights rather "the importance of public discussions prior to a vote" (Peter, 2011, p. 31). Citizens' opinions and political will are not considered synonymous with their private preferences, but as the transformed outcomes of processes of argumentation and intersubjective scrutiny (Bohman \& Rehg, 1997; Gutmann \& Thompson, 2004). This raises the question of the epistemic quality of these processes.

The epistemic dimension will also be more important in some settings than in others. With Mansbridge and Parkinson (2012) we approach the political process as a "deliberative system" and the epistemic, ethical and democracy functions as system level functions. Hence, each body, arrangement or single procedure within this system does not need to perform equally on all functions. Rather, in such systems, there will be a division of labour between different parts of the system, where a low score (for example on inclusion in one sub-system, say a governmental system of expert advisors) can be compensated with higher score elsewhere (to follow the same example, by an inclusive parliament and civil society). Deliberative democracy theory would regard the epistemic dimension to also be significant outside expert settings (Estlund, 2008; Habermas, 1996; Landemore, 2011). However, given the division of labour within the overall deliberative system, and the contention that legitimate expertise is to serve as a cognitive quality ensuring "filter", the epistemic dimension of deliberation is key not least when assessing the legitimacy of expert arrangements. Arguably, granting extra political power to experts is defensible if, and only if, doing so contributes to better and more truth-sensitive decisions (see also Martí, 2006). To assess the epistemic quality of expert deliberation is thus decisive from a legitimacy perspective, and an obvious, pressing task for research.

The question we ask is what epistemic quality in expert deliberations would include. Our approach is thus procedural: we are looking for more specific epistemically relevant features of deliberative processesvariables we can reasonably assume correlate with high epistemic quality of decisions - and not outcomeoriented criteria meant to capture decision quality directly. We thus avoid the difficult question of what a "good outcome" is in this or that case. This is not to deny that we can have reasonable discussions about general standards of good outcomes (they must be in accordance with fair principles, the best available evidence, etc.). However, to analyse the Commission's expert group experts from an outcome perspective, we would need clear definitions of good and bad decisions in the myriad of cases these experts give advice on. In some cases where experts give projections of future events, researchers could check in retrospect whether experts were right (see for example Tetlock, 2005). However, the Commission's experts are engaged in a range of activities other than prediction-making, such as providing reviews of existing research, mapping national experiences, recommending regulatory standards and schemes, etc. Moreover, expert judgments, even if sound, may or may not result in good decisions in the end, depending on the behaviour of other political actors and policy-making bodies, as well as unpredictable incidents and developments. This makes the quality of end results of political processes in which experts have been involved an unreliable indicator of the involved experts' epistemic performance.

Our focus more specifically will be on to the extent to which expert discourse is 1 ) influenced by technical expertise, 2) regulated by epistemically optimal respect and inclusion norms, 3) focused on politically relevant and applicable knowledge, and 4) approaching questions involving moral judgment and standard setting competently. This is not an exhaustive list of relevant variables, but as we will elaborate more on in the next section, we hold these four to be essential: if expert deliberations are unaffected by expert knowledge, regulated by norms that are detrimental to knowledgeseeking, politically irrelevant and inapplicable, and approach non-factual, value-laden questions incompetently, there is reason to suspect that the epistemic quality of deliberations is poor and expert performance low.

Deliberative democracy literature includes several studies of deliberative qualities. Methods applied and overall focus vary from questionnaires measuring the experience of deliberators to single case studies connecting the amount and characteristics of deliberation to policy outcomes (for a review, see Neblo, 2007). The problem, in particular when we are assessing expert discourse, is the limited attention to our variables 1 ) and 2). An illustration of this is the branch of this literature which aims to measure deliberative qualities by applying quantitative coding schemes to transcripts of deliberation (notable and often cited contributions here include Bächtiger, Niemeyer, Neblo, Steenbergen, \& Steiner, 2010; Steenbergen, Bächtiger, Spörndli, \& Steiner, 2003; Stromer-Galley, 2007). First, these devices typically connect deliberative quality to explicit reason-giving. However, one could easily imagine highquality expert deliberations taking place in a rather implicit fashion on the basis of common expert knowledge. In cases where non-expert deliberations would perhaps profit from explicit discourse to enlighten the subject, expert deliberations are already relatively enlightened and would rather improve by sidestepping some rounds of reason-giving and move on to deliberations on more sophisticated claims. Explicitness as an indicator of the epistemic quality of expert deliberations is thus dubious since the correlation with high expert knowledge influence on deliberations (i.e. variable 1 ) is possibly negative, and at least highly variable. Secondly, these coding devices do not distinguish clearly between the epistemic, respect and inclusion dimensions, and as far as they 
do, they seem to focus more on respect and inclusion. It is, however, likely that these dimensions contribute in somewhat different directions, in that high scores for standard respect and inclusion variables such as participation and respect for the demands that are raised, are not necessarily epistemically optimal (our variable 2 ).

Compared with the literature on deliberative democracy, science and technology studies concentrate more specifically on expert behaviour and expertise institutionalisation (see for example Galison \& Stump, 1996; Jasanoff, 1995, 2007, 2012; Latour, 1987, 2004). However, the focus is not really on our variables 1 ) and 2 ), since this branch of studies typically concentrates on how actual developments in the fields of knowledge, science and expertise (what is accepted as "scientific", scientific practice, the outcomes of controversies among scientists and experts etc.) are shaped by other factors than level of expertise and epistemic performancesuch as historical path-dependencies, competition between incommensurable approaches and research programs, value-based disagreements, etc.

This contrasts with literature on the philosophy of science, with its continual discussions of epistemic parameters in science and similar knowledge and truthseeking practices. A core concern in the philosophy of science canon from the logical positivists of the Viennacircle, the "falsificationism" and "critical rationalism" of Karl Popper (1963) and onwards (for an introduction, see Rosenberg, 2011), is to identify more closely what it means for scientific knowledge to be "objective", "valid", "true", etc. Another strand of thought has its origins in classical sociology of knowledge and circles around the idea of a "scientific ethos" (for an influential articulation see Robert Merton's (1973) CUDOS-norms, "communalism, universalism, disinterestedness and organized scepticism"). These two traditions, together with ideas of the constitutive norms of "the community of inquirers", originate in part in the pragmatist tradition, from Charles Sanders Peirce to John Dewey (contrast here Apel, 1994; Haack, 1993 with Rorty, 1982, 1991). They also owe something to the liberal tradition, not least the works of John Stuart Mill, and are the backdrop of more recent philosophy of science contributions focused on spelling out criteria of good science. Such theories also link up to the notion of deliberation and theories of deliberative democracy (Kitcher, 2001, 2011; Longino, 2002, see also Anderson, 1995a, 1995b).

However, what is lacking even in these recent contributions is a proper understanding of how epistemic parameters and standards of good expert behaviour transform when we move from science to politics. This is reflected in the overlooking of our variables 3) and $4)$, the extent to which expert deliberations in political processes are focused on politically relevant and applicable knowledge and competent in its dealings with moral concerns and questions of standard setting. The approach of Philip Kitcher $(2001,2011)$ is illustrative.
For our purposes, it is promising that Kitcher connects epistemic quality to collective practices of deliberation and to the fulfilment of norms and standards of such practices. ${ }^{1}$ Furthermore, he denies that questions of values and norms are external to scientific practice (Kitcher, 2001, pp. 85-92, 2011). Defenders of standard ideas of value-freedom in science, from Max Weber and Karl Popper to contemporary defenders (see Haack, 1993, 2001), typically accept that research questions and applications of research should be "value-relevant" (Weber, 1949) and "significant" (Haack, 1993), but argue for a "pure" stage of theory testing, or "context of justification" (see Reichenbach, 1938), where ethical and political considerations have no role. Kitcher notes that already on this view, the scientific institution needs to be engaged by democratic deliberative processes, since value-laden questions of what to do research on and how to apply findings cannot be left solely to the scientists (Kitcher, 2001, pp. 117-146). This is even more so as the idea of "pure" theorytesting, fully distinguished from societal values and broader standard setting processes, cannot be upheld. ${ }^{2}$

Kitcher's conception of scientific inquiry as part of broader deliberative processes no doubt has affinities with the deliberative system conception of expert inquiries in political processes. However, even if he recognises that ethical and political considerations are an integral part of truth-seeking practices, he has relatively little to say about how to approach such considerations in an epistemically optimal way (our variable 4). Furthermore, good epistemic performance in science, even in Kitcher's account of a socially and politically embedded science, is not quite the same as good epistemic performance when operating as expert in political processes, since the latter hinges centrally on an orientation towards politically relevant and applicable knowledge (our variable 3 ). Also this falls outside the scope of Kitcher's discussions.

There is thus a need to supplement existing literature. The next section will elaborate on our four variables, relating them conceptually to the idea of expertise as a truth-facilitating filter in political processes in order to substantiate further why we believe they are central to assessments of expert deliberations' epistemic quality. Or to put it differently, if "( $\mathrm{t}$ )he epistemic function of a deliberative system is to produce preferences, opinions, and decisions that are appropriately informed by facts and logic and...relevant reasons" (Mansbridge \& Parkinson, 2012, p. 11), what kind of expert deliberations would we need, given experts' particular task to fulfil this function?

\footnotetext{
1 This distinguishes Kitcher's works from the philosophy of science branch that has attempted to demarcate science from non-science based on definitions of particular characteristics of propositions and theories.

${ }^{2}$ Kitcher delivers a set of more specific arguments that cannot be assessed here.
} 


\section{Assessing the Epistemic Quality of Expert Deliberations: Four Key Variables}

\subsection{Informed by Technical Expertise}

A first major requirement would be that those who are referred to or refer to themselves as experts are "real" experts and deliberate on the basis of their expertise. "Expertise" is both a comparative and a threshold concept: experts are those within a domain that "possess a substantial body of truths" and that "have more beliefs (or high degrees of belief) in true propositions and/or fewer beliefs in false propositions within that domain than most people do (or better than the vast majority of people do)" (Goldman, 2011, p. 15). Experts in short know a lot about something and more than most others do. The more particular substance of that "something" will vary immensely between domains-there are experts on nanotechnology, on labour market economics, on environmental regulation, on international trade law, etc. Also, institutional affiliation could very well vary: the Commission's expert group members are scientists, but also bureaucratic officials with relevant regulatory experience, stakeholder representatives and "counter expertise" (Gornitzka \& Sverdrup, 2008, 2010). However, generally, experts relied on in policy and decision-making are expected to contribute with an extra, substantial set of "facts" (Mansbridge \& Parkinson, 2012) or "truths" (Goldman, 2011) on state of affairs and effects of interventions. This is often referred to as "technical expertise" (Collins \& Evans, 2002), and when experts are regarded as truth-facilitators in politics, this is intimately linked to the belief that their deliberations are informed relevantly by such expertise. Our variable 1 ) addresses whether this belief is empirically founded.

\subsection{Regulated by Epistemically Optimal Respect and Inclusion Norms}

Secondly, for deliberations to be "informed by facts and logic" and "relevant reasons", it seems vital that they are regulated by the right kind of respect and inclusion norms. Respect and inclusion are also separate functions of democratic politics, both with independent normative value, but the idea of our variable 2 ) is to pinpoint the extent to which expert deliberations are regulated by respect and inclusion norms that are optimal for fulfilling the epistemic function.

Good epistemic practice implies a certain morality of respect and inclusion (e.g. Robert Merton's (1973) idea of a scientific ethos). A contemporary account is given by Helen Longino (2002, pp. 128-135) in her argument for why inequality in "cognitive authority" is compatible with equality in "intellectual authority": to include in conversation everyone with something reasonable and relevant to say, irrespective of their social and cultural background, and to assess arguments irre- spective of who are pursuing them. As Longino notes, there is no need to impose this idea of equal intellectual authority and the norms of respect and inclusion that follow on good epistemic practice from the outside, as this norm set seems to be implied by what it means to perform such practices successfully.

The implicit morality of proper investigation may, in concrete cases, imply both "more inclusion" and "more respect". Historically, there are several examples of how groups which were previously excluded from this or that epistemic practice and regarded as a priori inferior, are at some point included in the practice and granted equal intellectual authority for independent moral reasons, but also because it serves truth-seeking and sound inquiries (Anderson, 1995a, 1995b). Howev$\mathrm{er}$, in other cases the result could in fact be "less inclusion" and "less respect": in epistemically optimal deliberations, people can very well end up with being excluded and dismissed if their arguments turn out to be wrong or irrelevant (Lafont, 2006; Martí, 2006). ${ }^{3}$ This is why discourses are typically bounded and participation restricted in institutions where obtaining the truth is imperative (Alexander, 2005, pp. 128-130). Consider legal adjudications (set out to track "right" verdicts), but also science: “...professional journals refuse to publish claims that the editors believe are not properly substantiated, and faculties and laboratories refuse to employ those who hold what in the opinion of those faculties and laboratories are outlandish views" (Alexander, 2005, p. 128). It can, therefore, be a long way from the democratic ethos of inclusion and respect for all, in principle irrespective of their epistemic contribution, to the inclusion and respect structures that follows from epistemically optimal deliberations. It is, however, the latter which epistemicallyoriented assessments of deliberations must strive to identify and assess, and that our variable 2 seeks to address.

\subsection{Focused on Politically Relevant and Applicable Knowledge}

Thirdly, truth-seeking in science is often equated with truth-seeking proper. However, truth-seeking goes on in different institutional contexts, and even if truthseeking practices have overlapping features across con-

\footnotetext{
3 There is a tradition going back at least to John Stuart Mill which contends that a diversity of arguments and perspectives, pursuing investigations and discussions from as large a variety of relevant angles as possible, will facilitate better outcomes (see also Anderson (2006). Landemore (2011) connects this argument to more recent "wisdom of crowds research". This draws attention to how democratic inclusion may have instrumental merits. This point must however not be confused with an argument saying that the broadest possible participation always improves on outcomes (Mansbridge \& Parkinson, 2012; Marti, 2006; Mutz 2006, 2013; Rothstein, 2011).
} 
texts, what they include and imply may vary. More specifically, our variable 3 reflects the fact that the institutional goals of science and politics are distinct. Whereas the official institutional goal of science is to seek valid knowledge, "truth" and "objectivity", the ultimate goal of politics is to reach collectively binding decisions. Political decisions ought to be truth-sensitive and based on knowledge, "facts and logic" and "relevant reasons" (Mansbridge \& Parkinson, 2012), but which reasons are relevant or which "truths" are "significant" (Haack, 1993) will be shaped and restrained by the fact that the truth-seeking is part of a decisionmaking process. The knowledge brought forward and relied on in the deliberations of democratic politics thus needs to be politically relevant and significant; it should reflect what is possible and desirable, given both relevant political actors' different preferences and assessments of what may be common political goals and norms, and what is feasible to implement in practice (as far as the issues in question raise questions of governmental implementation and regulation). From an epistemic point of view, this requirement applies to all deliberation in politics, and as far as experts are particularly assigned to optimise epistemic outputs, no less to expert deliberations; in this setting political considerations of relevance and applicability are not external (legitimate or illegitimate) curtailments, as when deliberations in science adapt to the institutional goals of politics, but rather an internal epistemic demand reflecting how politics is not science, but a distinct context of collective will-formation and decision-making.

\subsection{Approaching Questions Involving Moral Judgment and Standard Setting Competently}

Finally, politics concerns technical issues, but also questions about what we ought to do. From an epistemic point of view, this raises the question of whether there can be such a thing as "moral expertise", expertise on issues of what ought to be done, in addition to what lies within the scope of technical expertise. Kitcher articulates a common view when answering "no" (see also the classical formulation by Dahl, 1989). In the domain of normative questions, we are all, he says, equally experts or non-experts, and "our ethical discussions are adequate to the extent that they reach the conclusions that would have resulted from an ideal deliberation under conditions of mutual engagement" (Kitcher, 2011, p. 51).

But what if a group of trained moral experts are able to track these "ideal" conclusions better than any non-ideal moral conversation including all, trained and untrained in moral thinking and argumentation? This possibility spurs Peter Singer (1972, p. 117) to conclude that "moral expertise would seem to be possible" in a certain sense: "[s]omeone familiar with moral concepts and with moral arguments, who has ample time to gather information and think about it, may reasonably be expected to reach a soundly based conclusion more often than someone who is unfamiliar with moral concepts and moral arguments and has little time". Similarly, John Broome (2012, p. 9) argues that there can be moral experts "of a sort", those who "are practiced in accurate reasoning" on moral questions, who "know the range of alternative moral ideas that are available", who "know how to subject those ideas to rational testing", who can "refute bad arguments" in this domain, and who have "a trained sensitivity to moral, issues". ${ }^{4}$

Accordingly, a fourth key variable in assessment of expert deliberations' epistemic quality is whether, and the extent to which, normative questions are approached competently. Arguments of democratic respect and inclusion speak in favour of leaving the moral issues that may occur in such deliberations to citizens or their representatives, and as suggested by Dahl, Kitcher and others, epistemic concerns lead in the same direction, as long as there is no moral expertise among the deliberators. However, as far such "sort of" expertise is available, the epistemic quality of expert deliberations would depend on whether and how it is used. Moral expertise could here refer to a special competence in conceptualising and elaborating the meaning of norms, values and ends involved, expiring the implications of pursuing this or that end or of defining this or that value in one way or another, exploring normative conflicts and the consequences of such conflicts, etc. We could, however, also think of moral experts that enter "the kingdom of ends" and discuss the justifiability of norms and political aims, and of different interpretations, priorities and the balancing of normative ideas and ideals. A "justice expert" may argue that this or that is the appropriate metric of distributive justice and then suggest a principle of just distribution, say of health care, or may tell us that this or that is the reasonable way to approach conflicts between rights.

\section{The Epistemic Quality of Deliberation in European Commission Expert Groups: Do Researchers Investi- gate It-And Can They?}

\subsection{Existing Studies of European Commission Experts- Do They Evaluate Epistemic Performance?}

From a legitimacy perspective, it is, as we have argued, essential to investigate experts' epistemic performance and the quality of their deliberations-and we have now elaborated on a set of variables that seems decisive. Looking at the case of the European Commission's use of external expertise and the institutionalisation of a formalised expert group system-currently consisting

\footnotetext{
${ }^{4}$ Obviously, moral experts in this sense do not necessarily themselves act in morally superior ways.
} 
of 1575 groups (European Commission, n. d.)-it seems that existing studies have only sporadically touched upon this issue.

One branch of previous research clearly relates to questions of legitimacy. Mark Rhinard (2002) is assessing "the democratic legitimacy" of the EU committee system, Commission expert groups included, and looks at whether decision-making is 1) transparent in terms of who makes the decisions and which societal issues are at stake; 2) deliberative, allowing "different conceptions of the public interest" into the process and giving them "a fair and thoughtful hearing"; and 3) accountable, meaning that citizens have control over the policy-making system. Julia Metz (2014) has a similar ambition, concentrating on expert groups and applying Fritz Scharpf's (1999) concept of output legitimacy, a legitimacy standard that "demands effective problem solving, but also policy solutions to be in the public interest" (Metz, 2014, p. 268). Metz goes on focusing on the latter aspect and argues that expert groups are not open enough to achieve a suitable balance between effectiveness and inclusiveness. Finally, Åse Gornitzka and UIf Sverdrup (2010, p. 2) "map out the scale of involvement of scientists" in expert groups, and even if they do not explicitly "engage in any discussion of the appropriate level of scientific involvement" and "the potential democratic gains and losses of such involvement", they believe their study provides a crucial "factual basis" for such assessments.

A shared characteristic of these contributions is how they connect the legitimacy of the expert groups primarily to the extent of their democratic inclusiveness, not to the expert group members' epistemic performance. Rhinard (2002) and Metz (2014) both provide insights into aspects of how the experts deliberate, and, arguably, touches upon our variables 2, 3 and 4; whether and how "public interest" is included relates both to the political relevance and applicability of the deliberations, the level of competence in the handling of standard setting, and the question of epistemically optimal inclusion, whereas giving arguments "a thoughtful hearing" could be described as a truth-facilitating respect norm. The relevance here is, however, indirect and vague, as there is no question of a systematic focus of the epistemic merits of the expert group members' deliberations, and variable 1 is not addressed at all.

Another category of existing studies looks at knowledge utilisation and whether the Commission's use of expertise has a primarily problem-solving function or rather more strategic functions. Typically, such studies do not look specifically at expert group members and other experts' behaviour, but at how knowledge is perceived and utilised by the Commission for policy-making (see for example Boswell, 2008). There are also contributions including analyses of experts' perceptions and their role that shed some light on our research question, but this is not the main issue (Metz, 2013). A recent study systematically maps perceptions among scientists in expert groups of how the Commission employs scientific knowledge (Rimkute \& Haverland, 2014), but our variable 1 - whether such knowledge influences the experts' own deliberations, and the general question of how the experts themselves perform - is not addressed.

There are in addition other single studies of the Commission's expert groups, such as Torbjörn Larsson and Jarle Trondal's (2006) investigation into the Commission's organisation of the agenda-setting of policymaking, including the role of experts and consultative groups, but the focus here is on how to explain organisational and institutional features, rather than on how groups and group members perform according to cognitive criteria. Another sociologically-oriented study analyses expert group members' social resources and overlapping career trajectories as constitutive for common experiences and aspirations (Robert, 2010), but is silent on how this may affect their performance as proper experts.

\subsection{Why Not Check the Quality of Experts' Deliberation? Methodological and Other Interpretations}

We have to conclude that interest in our research question has thus far been highly limited; what we have found constitutes only a few studies with some indirect relevance for some of our variables. This (non-)finding could have several explanations. On some level, it may be an expression of relativist trends in the academic community, a belief that it is hard, even impossible, to distinguish better from worse, right from wrong, true from false. To study whether expert deliberations have epistimically optimal or even truth-facilitating characteristics, does presuppose some idea of "truth", or at least a notion of deliberation as having stronger or weaker epistemic merits, and if the latter is denied, studies of the kind we have been looking for here do not seem to make much sense. Alternatively, what we are witnessing reflects, not necessarily blatant relativism, but an attempt to remain politically neutral, and a sceptical attitude among researchers to utilising research in order to address questions of EU legitimacy and other such questions enmeshed in political controversy. But as the review above has showed, it is not really the case that those investigating the Commission's expert groups generally shy away from controversial issues or evaluative undertakings. What is missing is the particular evaluative undertaking of studying whether experts operate epistemically as they are supposed to.

Another reason could simply be that there still are so few studies on the Commission's expert groups; maybe the studies we are looking for are yet to come. However, so far, a research question that, from a legitimacy perspective at least, is highly urgent, has seem- 
ingly been given no priority whatsoever. This adds, moreover, to similar trends in other branches of relevant research (see Section 2).

A third interpretation may be that there is something wrong with our legitimacy analysis and that the cognitive quality of experts' deliberations and performance is not such a decisive topic after all. That this is the case, is, however, hardly controversial; as indicated, the idea of expertise as a truth-facilitating "filter" is well-established in theoretical discussions of normative legitimacy. This more ideal role of expertise is also assumed in empirical literature, for example in standard outlines of the official problem-solving function of expertise, and indeed by the Commission itself when it spells out principles and guidelines for the proper organisation and use of expert advice (see for example European Commission, 2002, pp. 9-10; European Commission, 2010, p. 10).

Our focus will therefore be on a fourth interpretation, namely that there may be methodological challenges, or perceived methodological challenges that make our research question hard or even impossible to investigate. Methodological literature on how to study elite behaviour often focuses on two obstacles, the access problem and the bias problem (see for example Harvey, 2011; Ostrander, 1993). As members of the knowledge elite, experts can be hard to access. Time is a scare resource, and people in elite positions typically have a lot scheduled. Elites may also have an interest in turning down requests from researchers in cases where publicity could spur criticism. In cases where they have an interest in going public, they may have a range of channels for doing so, and do not need a researcher to speak up for them. The bias problem applies in studies of elites and none-elites alike, insofar as people are more interested in "looking good" than in providing the researcher with accurate information. However, an extra bias problem tends to occur in studies of elites, as elite informants typically perform above average as communicators and self-presenters, and are thus more effective in getting other people to buy into their world view. This is a challenge for research that aims not only to capture what elites say they do, but also what they actually do.

There are, however, additional methodological challenges. For one thing, our focus is specific; the question is not how expert group members behave and think in general, but how they deliberate. Not all data and methods are equally adequate for this purpose. More importantly, there is a key problem of epistemic asymmetry between experts and non-experts: nonexperts often lack the ability to assess experts' arguments, explanations and judgments directly. This problem, referred to in social epistemology literature as "the layperson-expert problem" (Goldman, 2011), is often highlighted as an obstacle when citizens try to hold experts to democratic account, but is potentially also a grand obstacle when non-experts do research on experts, at least when the aim is, as in our case, to assess the experts' epistemic performance. It is hard to assess whether technical expertise, be it on medical technology, environmental law or agriculture, influence experts' deliberations (our variable 1), or whether a complex argument of distributive justice or moral responsibility is competently pursued (our variable 4) when the person making the assessment lacks this kind of technical and moral expertise. This or that may appear to be an "expert" contribution, but if you are a non-expert, how could you know?

In the next section, we will discuss the persuasiveness of these four methodological challenges when studying the epistemic performance of the Commission expert group experts. Is it likely that access and bias problems make researchers shy away from this line of research? Is the problem our specific focus on deliberation? Or is the key factor rather the deeper underlying problem of epistemic asymmetry?

\subsection{Data Adequacy and Methodological Challenges}

There seem to be, roughly speaking, four ways to approach a study into the Commission's expert groups. ${ }^{5}$ First, there is available background data on the groups in the Register of Commission Expert Groups, an online register of all groups that include information on policy area, responsible DG, mission/mandate, characteristics of individual members, etc. More background data, for example on the group members' careers, could be collected and systematised along similar lines. Secondly, there is the possibility of asking the experts themselves about their thinking and behaviour, interviewing them, or making surveys. Thirdly, there are public documents. Most of the groups publish meeting minutes or activity reports, and some produce also additional reports and policy documents. The Commission has also produced a set of documents on expertise and consultation policies, expert group guidelines, etc. (see European Commission, 2001, 2002a, 2002b, 2010a, 2010b), in addition to what may be of more specific policy documents with relevance for particular expert groups depending on mandate and policy field. Lastly, there is the opportunity to study the groups through observing their meetings.

A first obstacle may be our specific focus on deliberation. Experts could be asked in interviews or surveys about the qualities of their group deliberations, and background data could be used as a rough proxy for likely deliberative qualities, assuming for example that

\footnotetext{
${ }^{5}$ Experimental design has been important in establishing cognitive psychology findings on biases in how experts think (see for example Kahneman, 2011; Mercier, 2011). However, we are not interested in how experts think and interact in general, but in how a particular set of experts in EU policy-making behave.
} 
groups dominated by scientists are more likely to have deliberations influenced by relevant technical expertise and epistemically optimal respect and inclusion norms. An indicator such as the latter would, however, be highly indirect, and potentially substantial variation in actual epistemic performance among the groups would be swept under the carpet. With regard to interviews and surveys, there is the possibility of low response rates, in addition to the bias problem: that this line of research tell us more about how Commission expert group members perceive their deliberations and want others to perceive them, than about how they actually deliberate. Observation of group meetings would be a more direct and seemingly safer way of capturing the latter; access problems could occur, but standard bias problems would more or less disappear. In addition, documentary sources, from minute meetings to reports and policy documents produced by the groups, would most likely contain potential relevant information on both knowledge basis (variable 1), norms of discussions and inquiry (variable 2), policy relevance (variable 3 ), and the qualities of normative argumentation (variable 4). Once more, there could, however, be problematic discrepancies between how deliberative qualities and epistemic performance are reported in various documents and the actual qualities of deliberations. The persuasiveness of bias problems would depend on the level of document quality and report accuracy.

Consequently, despite the well-known access and bias problems of elite studies and the specific focus on deliberation, the study of our four variables seem to be, if not a straightforward endeavour, within reach providing researchers utilise a combination of observation and documentary analysis. There is, however, the additional obstacle of epistemic asymmetry which seems to be pervasive across data and methods. Studies based on observation, for example, may eschew access and bias problems, and seem perfect when the study object is how experts deliberate, but the problem of how researchers of expert deliberation-who more often than not are non-experts in the domains where these experts are experts - can assess the epistemic quality of these experts' performance remains. The problem is perhaps most obvious in the cases of variable 1 and 4: it can be hard to distinguish sophisticated knowledge from what seems to be sophisticated, advanced competence from what is only seemingly advanced, unless you yourself are an expert. The very same difficulty will, however, also easily occur when non-experts try to assess whether the knowledge which experts rely on and produce through their deliberations is politically relevant and applicable (variable 3 ). To evaluate the political significance, adequacy and applicability of proposals and recommendations of what to do can be hard if you lack substantive insight in the knowledge basis of the proposals/recommendations in question and the normative issues involved. The same goes for the identification of epistemically optimal respect and inclusion norms (variable 2). To determine which deliberators and arguments belong in truthfacilitating deliberations on this or that topic, and who and what should be filtered out, will often require both substantive technical expert knowledge and extensive standard-setting competence.

As far as there are methodological obstacles holding investigators back, it seems, therefore, that the real problem and the elephant in the room is the problem of epistemic asymmetry. It figures not as a standard problem in methodological literature on elite research, but in studies of knowledge elites, at least when assessments of epistemic performance is involved, it seems to take effect at a very basic level.

\section{Strategies for Research}

The question is how to get research on experts' epistemic performance going under such conditions. In this paper we have explained why concerns of political institutions' legitimacy make it imperative for research to investigate experts' epistemic performance; we have focused on experts' deliberations; elaborated on four key variables; and discussed whether the lack of attention to our research question and these variables in existing research on the Commission's expert groups, can be due to unsurpassable methodological obstacles. Is it in effect impossible, or at least too difficult, to do the research we ideally ought to be doing? The last section's discussion of available data, their merits and limits, makes it clear that the layperson-expert problem is not only an accountability problem, but also a general methodological problem for research on how knowledge elites perform. Future research and methodological discussions should focus more consistently on how to get around it.

We end this paper, therefore, by sketching five strategies for further exploration in such discussions, with a focus on the first and fourth of our listed variables; as suggested in the previous section, if epistemic asymmetries make it hard to determine scores on 1 and 4 , they are likely to complicate research on 2 and 3 as well.

The first strategy would be to increase one's expertise and competence in relevant domains. Harry Collins and Robert Evans (2007) distinguish between the ability to "contribute" in a domain of technical expertise ("contributory expertise"), and to have enough competence in this domain to be able to make sense of what its contributory experts are saying and doing ("interactional expertise"). In most cases the aim cannot be to diminish epistemic asymmetry: typically, high levels of interactional expertise will not abolish the layperson-expert problem, but it can very well reduce it. High levels of interactional 
expertise in combination with training in normative reasoning can also contribute to increased moral competence and levels of moral expertise.

The second strategy is to reduce the problem of epistemic asymmetry by picking cases of expert deliberation where the initial asymmetry is low or limited, for example deliberations in domains that are close or not too far from one's own domain of expertise, or expert groups with mandates that are fairly non-technical, do not raise complex questions of standard-setting, etc. in order to increase the likelihood that one understands the substance of what is going on.

Thirdly, a negative approach could be taken and expert group discourse investigated through documents or by way of observation in search of what is certainly not expertise. Examples here would be exchanges of polite phrases or other trivial types of discussion without any substantive claims being made about the questions at hand, or deliberations that are off topic. Naturally, this strategy is helpful only in identifying expert deliberations that are clearly not expertise-based, and cannot be employed in harder cases to distinguish between the genuine expert and the amateur or quasiexpert dressing up as an "expert". However, in actual empirical studies it can be a relevant first step.

A fourth strategy is to look at facets of the deliberations that are likely to indicate epistemic quality and that even non-experts could assess. An example with relevance for variable 1 is explicit expressions of epistemic modesty, when deliberators draw attention to the limits of their expertise; where their competence ends, what is still unknown or uncertain, what other experts might disagree with, etc. An example with relevance for variable 4 is the extent to which deliberators make explicit attempts to distinguish between technical considerations and value-based assessments; singling out the latter to put them aside, deliberating on both, but separately, etc.

A fifth strategy would be to identify and investigate promising extra-deliberative indicators of deliberative quality. Background data could be searched through to single out experts with the right credentials and merits for the task. Questionnaires sent to expert group members or qualitative interviews consciously designed to minimise the bias problem could be used to trace epistemic attitudes. Document analysis in combination with interviews of relevant Commission officials could shed light on epistemic parameters in selection and recruitment procedures.

It should be noted that these strategies are not meant to be mutually exclusive. Rather, combining them could contribute to increased validity. The aim, moreover, has not been to provide research strategies that make epistemic asymmetry as methodological challenge in studies of knowledge elites vanish. We believe our approach is promising, but also that the challenge it addresses is persistent and specific cases could easily occur. Due to their lack of contributory expertise, non-expert researchers could misperceive their level of interactional expertise (i.e. the first strategy), assume that the initial epistemic asymmetry is more limited than it is (i.e. the second strategy), identify a sequence of non-trivial expert exchange as trivial phrases (i.e. the third strategy), etc. In the end, the ultimate test of the viability of our proposed strategies is the extent to which they may inspire high quality empirical research. Obviously, for this to happen, more detailed work on research questions, operationalisation and methodological design is needed.

\section{Acknowledgements}

Previous versions of this paper have been presented at a workshop at ARENA-Centre for European Studies, University of Oslo, June 2014, and at the workshop "Deliberation after consensus", Paris, 20-21 November 2014. We thank participants on these occasions and three anonymous reviewers for valuable comments.

\section{Conflict of Interests}

The authors declare no conflict of interests.

\section{References}

Alexander, L. (2005). Is there a right of freedom of expression? Cambridge, UK: Cambridge University Press.

Anderson, E. (1995a). The democratic university: The role of justice in knowledge production. In E. F. Paul, F. D. Miller, \& J. Paul (Eds.), The just society. Cambridge: Cambridge University Press.

Anderson, E. (1995b). Knowledge, human interests, and objectivity in feminist epistemology. Philosophical Topics, 23(2), 27-58.

Anderson, E. (2006). The epistemology of democracy. Episteme, 3(1-2), 8-22.

Apel, K. O. (1994). Sense-critical realism: A transcendental-pragmatic interpretation of C. S. Peirce's theory of reality and truth. In J. De Groot (Ed.), Nature in American philosophy (Studies in philosophy and the history of philosophy) (Vol. 42, pp. 37-52). Washington, DC: CUA Press.

Bächtiger, A., Niemeyer, S., Neblo, M., Steenbergen, M. R., \& Steiner, J. (2010). Disentangling diversity in deliberative democracy: Competing theories, their blind spots and complementarities. Journal of Political Philosophy, 18(1), 32-63.

Bohman, J., \& Rehg, W. (1997). Deliberative democracy: Essays on reason and politics. Cambridge, MA: MIT press.

Boswell, C. (2008). The political functions of expert knowledge: Knowledge and legitimation in European Union immigration policy. Journal of European 
Public Policy, 15(4), 471-488.

Broome, J. (2012). Climate matters: Ethics in a warming world (Norton global ethics series). New York, NY: WW Norton and Company.

Christiano, T. (2012). Rational deliberation among experts and citizens. In J. Mansbridge \& J. R. Parkinson (Eds.), Deliberative systems: Deliberative democracy at the large scale. Cambridge: Cambridge University Press.

Collins, H. M., \& Evans, R. (2002). The third wave of science studies of expertise and experience. Social studies of science, 32(2), 235-296.

Collins, H. M., \& Evans, R. (2007). Rethinking Expertise. Chicago: Chicago University Press.

Dahl, R. A. (1989). Democracy and its Critics. New Haven, CT: Yale University Press.

Estlund, D. (1992). Who's afraid of deliberative democracy-on the strategic/deliberative dichotomy in recent constitutional jurisprudence. Texas Law Review, 71, 1437-1477.

Estlund, D. (1993). Making truth safe for democracy. In D. Copp, J. Hampton, \& J. Roemer (Eds.), The idea of democracy (pp. 71-100). Cambridge: Cambridge University Press.

Estlund, D. (1994). Opinion leaders, independence, and Condorcet's jury theorem. Theory and Decision, 36(2), 131-162.

Estlund, D. (1997). Beyond fairness and deliberation: The epistemic dimension of democratic authority. In J. Bohman, \& W. Rehg (Eds.), Deliberative democracy: Essays on reason and politics (pp. 173-204). Cambridge, MA: MIT Press.

Estlund, D. (2008). Democratic authority: A philosophical framework. Princeton: Princeton University Press.

European Commission. (2001). European governanceA white paper (9289410612, 25.7.2001: COM(2001) 428 final). Brussels: European Commission.

European Commission. (n.d.). Register of Commission Expert Groups. Retrieved from http://ec.europa.eu/ transparency/regexpert/index.cfm

European Commission. (2002a). Communication from the Commission on the collection and use of expertise by the Commission: principles and guidelines"Improving the knowledge base for better policies" (11.12.2002: COM (2002) 713 final). Brussels: European Commission.

European Commission. (2002b). Communication from the Commission. Towards a reinforced culture of consultation and dialogue-General principles and minimum standards for consultation of interested parties by the Commission (11.12.2002: COM(2002) 704 final). Brussels: European Commission.

European Commission. (2010a). Commission staff working document. Accompanying document to the communication from the President to the Commission-Framework For Commission Expert Groups:
Horizontal rules and public register (10.11.2010: SEC(2010) 1360 final). Brussels: European Commission.

European Commission. (2010b). Communication from the President to the Commission-Framework for Commission expert groups: Horizontal rules and public register (10.11.2010: C(2010)7649 final). Brussels: European Commission.

Galison, P., \& Stump, D. J. (1996). The disunity of science: Boundaries, contexts, and power. Redwood City, CA: Stanford University Press.

Gesang (2010). Are moral philosophers moral experts? Bioethics, 24(4), 153-159. Retrieved from http://plato.stanford.edu/archives/sum2014/entrie s/reichenbach

Goldman, A. I. (2011). Experts: Which ones should you trust? In A. Goldman \& D. Whitcomb (Eds.), Social Epistemology: Essential Readings (pp. 109-135). Oxford, UK: Oxford University Press.

Goodin, R. E. (2003). Reflective democracy. Oxford, UK: Oxford University Press.

Gornitzka, Å., \& Sverdrup, U. (2008). Who consults? The configuration of expert groups in the European Union. West European Politics, 31(4), 725-750.

Gornitzka, Å., \& Sverdrup, U. (2010). Enlightened decision making. The role of scientists in EU governance (ARENA Working Paper, Vol. 5/10). Oslo, Norway: ARENA.

Gutmann, A., \& Thompson, D. (2004). Why deliberative democracy? Princeton: Princeton University Press.

Haack, S. (1993). Evidence and inquiry: Towards reconstruction in epistemology. Oxford: Blackwell.

Haack, S. (2001). Manifesto of a passionate moderate: Unfashionable essays. Chicago, IL: University of Chicago Press.

Habermas, J. (1996). Between facts and norms. Cambridge, MA: MIT Press.

Harvey, W. S. (2011) Strategies for conducting elite interviews. Qualitative research, 11(4), 431-441.

Jasanoff, S. (1995). Handbook of science and technology studies. Thousand Oaks, CA: Sage.

Jasanoff, S. (2007). Designs on nature: Science and democracy in Europe and the United States. Princeton: Princeton University Press.

Jasanoff, S. (2012). Science and public reason. New York: Routledge.

Kahneman, D. (2011). Thinking, fast and slow. London: Penguin Books.

Kitcher, P. (2001). Science, truth, and democracy. Oxford, UK: Oxford University Press.

Kitcher, P. (2011). Science in a democratic society. New York, NY: Phrometeus Books.

Lafont, C. (2006). Is the ideal of deliberative democracy coherent? In S. Besson \& J. L. Martí (Eds.), Deliberative democracy and its discontents. Hampshire, England: Ashgate Publishing Itd.

Landemore. (2011). Democratic reason. New Haven, 
CT: Yale University Press.

Larsson, T., \& Trondal, J. (2006). Agenda setting in the European Commission: How the European Commission structure and influence the EU agenda. In A. Türk (Ed.), EU Administrative governance (pp. 1143). Cheltenham, UK: Edward Elgar Publishing.

Latour, B. (1987). Science in practice. Cambridge, MA: Harvard University Press.

Latour, B. (2004). Politics of Nature. Cambridge, MA: Harvard University Press.

Longino, H. E. (2002). The fate of knowledge. Princeton: Princeton University Press.

Mansbridge, J., \& Parkinson, J. R. (Eds.) (2012). Deliberative systems: Deliberative democracy at the large scale. Cambridge, UK: Cambridge University Press.

Martí, J. L. (2006). The epistemic conception of deliberative democracy defended. Reasons, rightness and equal political autonomy. In S. Besson \& J. L. Martí (Eds.), Deliberative democracy and its discontents (pp. 27-56). Hampshire, England: Ashgate Publishing Itd.

Mercier, H. (2011). When experts argue: Explaining the best and the worst of reasoning. Argumentation, 25(3), 313-327.

Merton, R. K. (1973). The normative structure of science. In R. K. Merton \& N. W. Storer (Eds.), The sociology of science, theoretical and empirical investigations. Chicago: The University of Chicago Press.

Metz, J. (2013). Expert groups in the European Union: A sui generis phenomenon? Policy and Society, 32(3), 267-278.

Metz, J. (2014). EU Commission expert groups between inclusive and effective policy-making. In C. Holst (Ed.), Expertise and democracy (ARENA Report No 1/14, Vol. 1, p. 263-291). Oslo, Norway: ARENA.

Moodie, J. (2011). The European Commission and European technology platforms: Managing knowledge and expertise in the development of European research and technology policy (PhD thesis). University of Newcastle upon Tyne, UK.

Mutz, D. C. (2006). Hearing the other side: Deliberative versus participatory democracy. New York: Cambridge University Press.

Mutz, D. C. (2013). Reflections on hearing the other side, in theory and in practice. Critical Review, 25(2), 260-276.

Neblo, M. A. (2007). Family disputes: Diversity in defining and measuring deliberation. Swiss Political Science Review, 13(4), 527-557.

Ostrander, S. (1993). "Surely you're not in this just to be helpful". Access, rapport and interviews in three studies of elites. Journal of Contemporary Ethnography, 22(1), 7-27.

Peter, F. (2007). Democratic legitimacy and proceduralist social epistemology. Politics, Philosophy and Economics, 6(3), 329-353.

Peter, F. (2011). Democratic legitimacy. New York, NY:
Routledge.

Popper, K. R. (1963). Conjectures and refutations. New York, NY: Routledge.

Reichenbach, H. (1938). Experience and prediction: An analysis of the foundations and the structure of knowledge. Chicago: The University of Chicago Press.

Rhinard, M. (2002). The democratic legitimacy of the European Union committee system. Governance, 15(2), 185-210.

Rimkutè, D., \& Haverland, M. (2014). How does the European Commission use scientific expertise? Results from a survey of scientific members of the Commission's expert committees. Comparative European Politics. doi: 10.1057/cep.2013.32

Robert, C. (2010). Who are the European experts? Profiles, trajectories and expert "careers" of the European Commission. French Politics, 8(3), 248-274.

Rorty, R. (1982). Consequences of pragmatism: Essays, 1972-1980. Minneapolis, MN: University of Minnesota Press.

Rorty, R. (1991). Objectivity, relativism, and truth: Philosophical papers (Vol. 1). Cambridge, UK: Cambridge University Press.

Rosenberg, A. (2011). Philosophy of science: A contemporary introduction. New York, NY: Routledge.

Rothstein, B. (2011). The quality of government: Corruption, social trust, and inequality in international perspective. Chicago, IL: Chicago University Press.

Schaefer, G. (2002). Governance by Committee: The role of committees in European policy-making and policy implementation. Luxembourg: European Communities.

Scharpf, F. W. (1999). Governing in Europe: Effective and democratic? Oxford, UK: Oxford University Press.

Singer, P. (1972). Moral experts. Analysis, 32(4), 115117.

Steenbergen, M. R., Bächtiger, A., Spörndli, M., \& Steiner, J. (2003). Measuring political deliberation: A discourse quality index. Comparative European Politics, 1(1), 21-48.

Stromer-Galley, J. (2007). Measuring deliberation's content: A coding scheme. Journal of Public Deliberation, 3(1), Article 12.

Talisse, R. B. (2004). Does public ignorance defeat deliberative democracy? Critical Review, 16(4), 455463.

Tetlock, P. (2005): Expert political judgment: how good is it? How can we know? Princeton, NJ: Princeton University Press.

Trondal, J. (2001). Is there any social constructivistinstitutionalist divide? Unpacking social mechanisms affecting representational roles among EU decision-makers. Journal of European Public Policy, 8(1), 1-23.

Weber, M. (1949). Objectivity. social science and social 
policy. In E. Shils \& H. Finch (Eds.), The methodology of the social sciences (pp. 49-112). New York: Free Press.
Weinshall, M. (2003). Means, ends, and public ignorance in Habermas's theory of democracy. Critical Review, 15(1-2), 23-58.

\section{About the Authors}

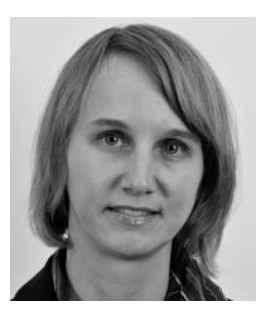

\section{Dr. Cathrine Holst}

Cathrine Holst is a Senior Researcher at ARENA-Centre for European Studies, University of Oslo where she coordinates the project Why not epistocracy? (EPISTO). Holst's research interests are democratic theory, political epistemology, expertise politics, European studies, and gender studies. Recent publications are "Why democracy? On the relationship between gender democracy and gender equality in the EU", and "Jürgen Habermas on public reason and religion: Do religious citizen suffer an asymmetrical cognitive burden, and should they be compensated?" (with Anders Molander).

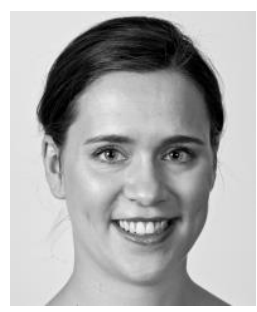

\section{Silje H. Tørnblad}

Silje H. Tørnblad is PhD Fellow and part of the EPISTO research group at ARENA-Centre for European Studies, University of Oslo. Her research interests include the democratic legitimacy of expert arrangements in the EU, EU institutions and European political economy. She obtained her MSc in European Political Economy from the London School of Economics and Political Science, and has previously worked for Cicero Centre for International Climate Research at the University of Oslo. 